\title{
Early resumption of sexual intercourse and its determinants among postpartum Iban mothers
}

\author{
M Radziah ${ }^{1}$, K Shamsuddin ${ }^{2}$, Jamsiah $\mathbf{M}^{2}$, M Normi ${ }^{3}$, TH Mohd Zahari ${ }^{4}$, \\ AT Nur Syimah ${ }^{4}$, M Nor Asiah ${ }^{4}$
}

\author{
${ }^{1}$ State Health Department, Kuching, Sarawak, Malaysia \\ ${ }^{2}$ Department of Community Health, Faculty of Medicine, Universiti Kebangsaan, Malaysia \\ ${ }^{3}$ Institute of Biological Sciences, University of Malaya, Kuala Lumpur, Malaysia \\ ${ }^{4}$ Institute for Medical Research, Jalan Pahang, 50588 Kuala Lumpur, Malaysia
}

Received: 18 February 2013

Accepted: 22 March 2013

\section{*Correspondence:}

Dr. Nor Asiah Muhamad,

E-mail: nor_asiah@imr.gov.my

(C) 2013 Radziah M et al. This is an open-access article distributed under the terms of the Creative Commons Attribution License, which permits unrestricted use, distribution, and reproduction in any medium, provided the original work is properly cited.

\begin{abstract}
Introduction: Recurrent pregnancy with close child spacing can result from early resumption of sexual intercourse during the postpartum period. This would expose mothers to complications such as unsafe abortion, postpartum depression and premature birth. The aim of this study is to identify the factors associated with early resumption of sexual intercourse among postpartum Iban mothers.

Methods: This is a cross sectional study conducted in Sri Aman Division, Sarawak between $1^{\text {st }}$ July and $31^{\text {st }}$ August 2006. A total of 265 Iban mothers agreed to participate in this study. They were interviewed face-to-face using structured questionnaire. Any postpartum sexual intercourse at 6 weeks or less is considered an early resumption of sexual intercourse.

Results: Univariable analyses showed significant association between early sexual intercourse and use of contraceptive; mothers' and husbands' income; mothers who believed their husbands were sexually abstinent during their confinement period; mothers who stayed with their spouse after delivery; and those with high libido. Multivariable analysis showed only mothers' and husbands' income, use of contraceptive and those who believed their husbands practiced sexual abstinence during their confinement period were significantly associated with early resumption of sexual intercourse.

Conclusions: Counselling on postpartum resumption of sexual intercourse among Iban mothers should focus on these determinants to ensure a more effective counselling outcome among Iban mothers.
\end{abstract}

Keywords: Early resumption, Sexual intercourse, Postpartum mothers, Determinants, Family planning

\section{INTRODUCTION}

Women health has been an important agenda in the development of the nation. Improvement in women's health is one of the indicators for national health status. Many programmes have been developed nationally to ensure improvement in women's health is achieved which in turn will influence the formation of productive communities and health of the nation.
An important element that has been identified in women's healthcare is sexual practice during the postpartum period. WHO has outlined the guidelines in women healthcare during postpartum period and stated the importance of counselling related to resumption of sexual intercourse. Among other issues are postpartum physiological changes, risk of early repeat pregnancy and ovulation process, and last but not least decision making in family planning during this period. ${ }^{1}$ 
However in Asian communities, counselling services related to sexual practice has not been widely discussed. One of the reasons is the prevalent belief in the community that sexual issues are not publicly open for debate, thus hindering needed services and information from reaching the targeted group. ${ }^{2,3}$ Similar situations are also observed with varying degrees in Europe, the United States, Africa and Australia. ${ }^{4}$

Many factors which are biological, psychological and sociological can affect women's decision on their sexual practice after delivery. Such factors involve beliefs of traditional healthcare and religious which result in delay or non-delay of repeated pregnancy. ${ }^{6}$ Factors that affect early resumption of sexual intercourse are known vary according to places and communities. ${ }^{4-6}$

Recurrent pregnancy with close child spacing will affects family, socio economics, medical and psychosocial wellbeing. ${ }^{7,8}$ Other negative impacts reported are unsafe abortion and its complications, postpartum depression and premature delivery. 8,9

The aims of this study are to assess the prevalence and determine the factors associated with early resumption of sexual intercourse among postpartum Iban mothers.

\section{METHODS}

This was a cross sectional study involving 265 Iban postpartum mothers from 13 governments antenatal clinics in Sri Aman Division, in the state of Sarawak, Malaysia. Although Sri Aman Division has 16 antenatal clinics, these 13 clinics were chosen because they provide child immunisation service. Postpartum mothers were recruited when they brought their children for immunisation to these clinics. Data collection for this study was done between $1^{\text {st }}$ July and $31^{\text {st }}$ August 2006. The sample size was calculated using Epi Info software by CDC Atlanta. All respondents had face to face interviews conducted by 3 trained interviewers. The interviews were carried out in Malay language and respondents answered structured questionnaire which consists of 3 sections. The questionnaire contains questions on sociodemographic background, health care, belief and practice during postpartum period and record on delivery. The questionnaire was pre tested and validated at four government's antenatal clinics in Sri Aman Division. All respondents gave written consent. This study was approved by Research and Ethics Committee Medical Faculty Universiti Kebangsaan Malaysia and Medical and Research Ethics Committee. A total of 288 postpartum Iban mothers were approached and 265 mothers agreed to participate giving a 92\% response rate. The 23 mothers who did not participate had moved out from Sri Aman at the time of the study.

In this study, early resumption of sexual intercourse is defined as any vaginal intercourse which occurred within 6 weeks or earlier after delivery. Libido was measured using 2 of the 19-item Female Sexual Function Index (FSFI). ${ }^{10}$

\section{Statistical analysis}

Univariable analyses were carried out by using Pearson Chi Square to find the association between early resumption of sexual intercourse and type of delivery, mothers' and husbands' socio-demographic factors, reproductive profile, breast feeding, use of contraception, libido and some measures of postpartum living arrangement and care. The determinants were analysed by performing multivariable analysis using multiple logistic regression. The results are considered significant when $\mathrm{p}<0.05$ or $95 \%$ CI did not include 1 . All statistical analyses were carried out using SPSS version 11.5.

\section{RESULTS}

\section{Prevalence of Early Sexual Intercourse during Postpartum Period}

A total of 265 Iban mothers were interviewed and 192 $(72.5 \%)$ had resumed sexual practice at the time of the study. Of these 192 respondents, 99 (51.6\%) mothers had resumed sexual intercourse within the first 6 weeks after delivery. Among all respondents, the prevalence of early resumption of sexual intercourse after delivery was $37.4 \%$ (99/265). The earliest sexual intercourse was reported in week 2 , and almost all women had resumed sexual intercourse by week 24 postpartum. Mean period for sexual intercourse resumption among these mothers was at $7.2 \pm 3.6$ week.

\section{Factors that Influenced Early Resumption of Sexual Intercourse among Postpartum Iban Mothers}

The results significantly showed mothers who earned more than RM 1000 had early sexual intercourse during their postpartum period compared to those who earned less than RM 1000, $\mathrm{p}<0.05$. On the other hand, significantly more mothers with husbands' income less than RM 1000 had early postpartum sexual intercourse, $\mathrm{p}=0.040$ (Table 1). This study also found mothers who used contraceptive method had early sexual intercourse compared to those who did not use any contraceptive method $(45.3 \%$ vs $31.1 \%, \mathrm{p}<0.05)$ (Table 2 ).

Table 2 also shows factors such as staying together with spouse after delivery $(\mathrm{p}=0.004)$, believing husbands were sexually abstinent throughout their postpartum confinement $(\mathrm{p}=0.009)$, and higher interest for sex $(\mathrm{p}=$ 0.012) were significantly associated with early resumption of sexual intercourse among these postpartum Iban mothers.

In the multivariable analysis, mothers' and husbands' income, use of contraceptive and mothers who believed that their husbands were sexually abstinent during their postpartum confinement are found to be significant determinants for early resumption of intercourse among postpartum Iban mothers (Table 3). 
Table 1: Association between postpartum mother's and husband's sociodemographic characteristics and early resumption of sexual intercourse among postpartum Iban mothers.

\begin{tabular}{|c|c|c|c|c|c|c|}
\hline \multirow{3}{*}{ Characteristics } & \multirow{3}{*}{$n$} & \multicolumn{4}{|c|}{ Early sexual intercourse } & \multirow{3}{*}{$p$ value } \\
\hline & & \multicolumn{2}{|c|}{ Yes } & \multicolumn{2}{|c|}{ No } & \\
\hline & & $\mathbf{f}$ & $\%$ & $\mathbf{f}$ & $\%$ & \\
\hline \multicolumn{7}{|l|}{ I. Postpartum Mothers } \\
\hline Age (Years) & & & & & & 0.778 \\
\hline$\leq 19$ & 26 & 10 & 38.5 & 16 & 61.5 & \\
\hline $20-34$ & 182 & 70 & 38.5 & 112 & 61.5 & \\
\hline$\geq 35$ & 57 & 19 & 33.3 & 38 & 66.7 & \\
\hline Number of Children & & & & & & 0.777 \\
\hline 1 & 67 & 27 & 40.3 & 40 & 59.7 & \\
\hline $2-4$ & 162 & 60 & 37.0 & 102 & 63.0 & \\
\hline 5 or more & 36 & 12 & 33.3 & 24 & 66.7 & \\
\hline Religion & & & & & & 0.961 \\
\hline Christian & 246 & 92 & 37.4 & 154 & 62.6 & \\
\hline Others & 19 & 7 & 36.8 & 12 & 63.2 & \\
\hline Mother's Educational Level & & & & & & 0.147 \\
\hline Primary school & 106 & 34 & 32.1 & 72 & 67.9 & \\
\hline Secondary school or higher & 159 & 65 & 40.9 & 94 & 59.1 & \\
\hline Mother's occupation & & & & & & 0.979 \\
\hline Not working & 201 & 75 & 37.3 & 126 & 62.7 & \\
\hline Working & 64 & 24 & 37.5 & 40 & 62.5 & \\
\hline Mother's income (RM) & & & & & & $<0.05$ \\
\hline Less than 1000 & 246 & 83 & 33.7 & 163 & 66.3 & \\
\hline 1000 or more & 19 & 16 & 84.2 & 3 & 15.8 & \\
\hline \multicolumn{7}{|l|}{ II. Husband } \\
\hline Husband's Ethnicity & & & & & & 0.248 \\
\hline Iban & 229 & 99 & 43.2 & 130 & 56.8 & \\
\hline Others & 36 & 0 & 0.00 & 36 & 100.0 & \\
\hline Husband's Work Status & & & & & & 0.418 \\
\hline Working & 260 & 98 & 37.7 & 162 & 62.3 & \\
\hline Not working & 5 & 1 & 20.0 & 4 & 80.0 & \\
\hline Husband's Average Income/Month & & & & & & 0.004 \\
\hline Less than RM1000 & 208 & 87 & 41.8 & 121 & 58.2 & \\
\hline RM1000 or more & 57 & 12 & 21.1 & 45 & 78.9 & \\
\hline Husband's workplace & & & & & & 0.249 \\
\hline In same district & 230 & 89 & 38.7 & 141 & 61.3 & \\
\hline Out of district & 35 & 10 & 28.6 & 25 & 71.4 & \\
\hline Husband returns home daily & & & & & & 0.838 \\
\hline Yes & 226 & 85 & 37.6 & 141 & 62.4 & \\
\hline No & 39 & 14 & 35.9 & 25 & 64.1 & \\
\hline Type of house & & & & & & 0.064 \\
\hline Long house & 152 & 64 & 42.1 & 88 & 57.9 & \\
\hline Others & 113 & 35 & 31.0 & 78 & 69.0 & \\
\hline Type of family & & & & & & 0.815 \\
\hline Extended & 155 & 57 & 36.8 & 98 & 63.2 & \\
\hline Nuclear & 110 & 42 & 38.2 & 68 & 61.8 & \\
\hline $\begin{array}{l}\text { Presence of elders } \\
\text { (Mothers/Mothers-in-law/ others) }\end{array}$ & & & & & & 0.317 \\
\hline Yes & 211 & 82 & 38.9 & 129 & 61.1 & \\
\hline No & 54 & 17 & 31.5 & 37 & 68.5 & \\
\hline Maid/ Domestic Help & & & & & & 0.242 \\
\hline Not available & 242 & 93 & 38.4 & 149 & 61.6 & \\
\hline Available & 23 & 6 & 26.1 & 17 & 73.9 & \\
\hline
\end{tabular}

*Significant when $\mathrm{p}<0.05$ 
Table 2: Association between type of delivery, breast feeding practice, and reproductive and sexual-related factors, and resumption of early sexual intercourse among postpartum Iban mothers.

\begin{tabular}{|c|c|c|c|c|c|c|}
\hline \multirow{3}{*}{ Characteristics } & \multirow{3}{*}{$n$} & \multicolumn{4}{|c|}{ Early sexual intercourse } & \multirow{3}{*}{$p$ value } \\
\hline & & \multicolumn{2}{|c|}{ Yes } & \multicolumn{2}{|c|}{ No } & \\
\hline & & $\mathbf{f}$ & $\%$ & f & $\%$ & \\
\hline Type of Delivery & & & & & & 0.188 \\
\hline Normal without sutures & 99 & 42 & 42.4 & 57 & 57.6 & \\
\hline Others & 166 & 57 & 34.3 & 109 & 63.9 & \\
\hline Breastfed baby during 6 weeks postpartum period & & & & & & 0.200 \\
\hline Yes & 197 & 78 & 39.6 & 119 & 60.4 & \\
\hline No & 68 & 21 & 30.9 & 47 & 69.1 & \\
\hline Resumption of menstrual bleed & & & & & & 0.217 \\
\hline Yes & 189 & 75 & 39.7 & 114 & 60.3 & \\
\hline No & 76 & 24 & 31.6 & 52 & 68.9 & \\
\hline $\begin{array}{l}\text { Started family planning within } 6 \text { weeks postpartum } \\
\text { period }\end{array}$ & & & & & & 0.018 \\
\hline Yes & 117 & 53 & 45.3 & 64 & 54.7 & \\
\hline No & 148 & 46 & 31.1 & 102 & 68.9 & \\
\hline Decision on family planning use made by & & & & & & 0.188 \\
\hline Husband/spouse & 36 & 17 & 47.2 & 19 & 52.8 & \\
\hline Others & 229 & 82 & 35.8 & 147 & 64.2 & \\
\hline Decision on number of children wanted made by & & & & & & 0.250 \\
\hline Husband/spouse & 42 & 19 & 45.2 & 23 & 54.8 & \\
\hline Others & 223 & 80 & 35.9 & 143 & 64.1 & \\
\hline Stayed with spouse after delivery & & & & & & 0.040 \\
\hline Yes & 232 & 92 & 39.7 & 140 & 60.3 & \\
\hline No & 33 & 7 & 21.2 & 26 & 78.8 & \\
\hline $\begin{array}{l}\text { Believed husband was sexually abstinent throughout } \\
\text { the } 6 \text { week postpartum period }\end{array}$ & & & & & & 0.009 \\
\hline Yes & 227 & 92 & 40.5 & 135 & 59.5 & \\
\hline No & 38 & 7 & 18.4 & 31 & 81.6 & \\
\hline Reported frequent desire for sexual intercourse & & & & & & 0.012 \\
\hline Yes & 156 & 68 & 43.6 & 88 & 56.4 & \\
\hline No & 109 & 31 & 28.4 & 78 & 71.6 & \\
\hline Reported high desire for sexual intercourse & & & & & & 0.008 \\
\hline Yes & 192 & 81 & 42.2 & 111 & 57.8 & \\
\hline No & 73 & 18 & 24.7 & 55 & 75.3 & \\
\hline
\end{tabular}

*Significant when $\mathrm{p}<0.05$

Table 3: Multivariable analysis for early resumption of sexual intercourse among postpartum Iban mothers.

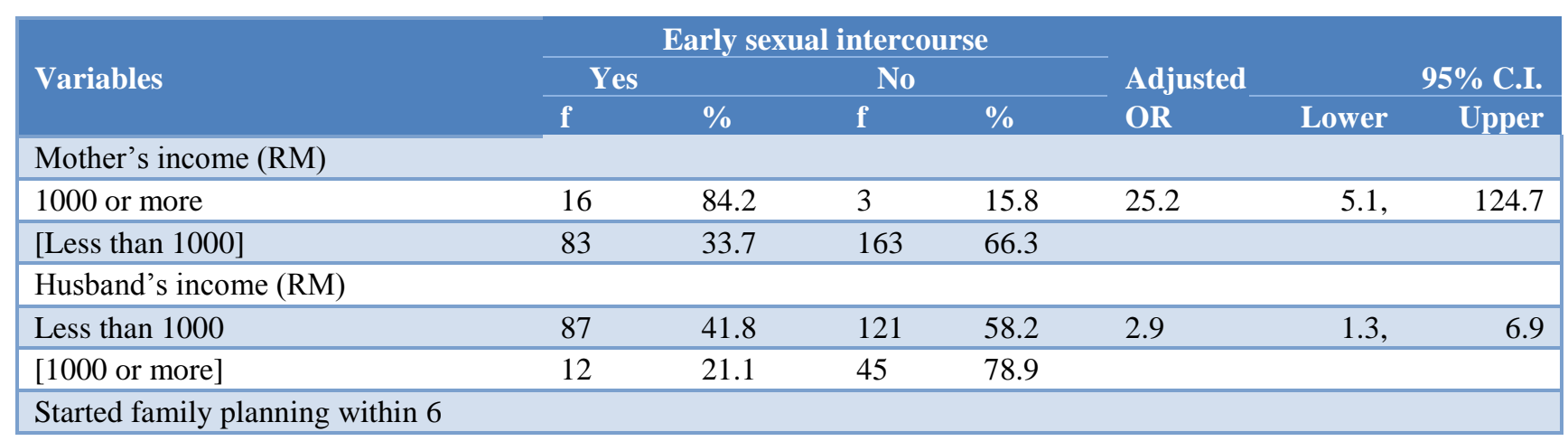




\begin{tabular}{|llllllll|}
\hline weeks postpartum period & & & & & & & \\
\hline Yes & 53 & 46.9 & 60 & 53.1 & 2.0 & 3.6 \\
\hline [No] & 46 & 30.3 & 106 & 69.7 & & \\
\hline $\begin{array}{l}\text { Believed husband was sexually } \\
\text { abstinence during the 6 week } \\
\text { postpartum period }\end{array}$ & & & & & & \\
\hline Yes & 92 & 40.5 & 135 & 59.5 & 2.9 & 1.1, & 7.8 \\
\hline [No] & 7 & 18.4 & 31 & 81.6 & & \\
\hline
\end{tabular}

[ ] Referent; Multivariable analysis adjusted for mothers' and husbands' socio-demographic characteristics, living arrangement during postpartum confinement, presence of elderly relatives, availability of domestic help, and sexuallyrelated factors including reported frequency and degree of sexual desire (libido).

\section{DISCUSSION}

Prevalence of early resumption of sexual intercourse, within the first six week after delivery, among all Iban mothers in this study was $37.4 \%$. This rate is similar to those reported by Thai ${ }^{11}$ and Nigerian ${ }^{12}$ mothers but lower than that experienced by Canadian women ${ }^{13}$. These differences in prevalence are due to differences in personal, as well as socio-cultural background, beliefs and practice of postpartum care in these mothers.

The variation in timing of sexual intercourse resumption from as early as week 2 and as late as 20 to 24 weeks postpartum, with a mean of week $7.2 \pm 3.6$ week is consistent with the study done in Thailand. ${ }^{14}$ The differences in length of time to sexual intercourse may be due to differences in adherence to traditional practices by the attending older female relatives, such as mothers or mothers-in-law, when providing or supervising postpartum care to these mothers.

This study showed mothers with higher average income were significantly more likely to resume sexual intercourse earlier compared to mothers who earned less. Similar result was found in a study in the Philippines where mothers' economic status influenced life style and birth spacing. Mothers with autonomy in decision making for their family are normally higher educated and earning their own income. ${ }^{15}$

In contrast, more postpartum Iban mothers whose husbands earned less than RM1000 had earlier sexual intercourse compared to those with husbands who earned more. Husbands with lower income may work closer to home or may be under employed giving them more free time to care and be with their wives who had just given birth. This finding is similar to the findings from two African studies by Cleland et al and Lawoyin et al which found husbands who earned less resumed sexual intercourse earlier compared to those who had higher income. ${ }^{16,17}$

This study found over $85 \%$ of the mothers believed their husbands were sexually abstinent during their postpartum confinement. More of these mothers allowed earlier resumption of sexual intercourse compared to those who did not trust their husbands. A study by Awusabo-Asare and Anarfi in Ghana also showed that mothers who reported having husbands who avoided sexual intercourse after delivery will resume earlier sexual intercourse in order to protect their relationship. ${ }^{18}$ These mothers were less adherent, or chose to stop following traditional practices which prohibit sexual intercourse during the postpartum period. Of concern to us, about a third of Iban postpartum mothers who had not started contraceptive use reported early resumption of sexual intercourse.

\section{CONCLUSION}

The prevalence of early resumption of sexual intercourse among all postpartum Iban mothers in the study is $37.4 \%$, with mean sexual resumption at $7.2 \pm 3.6$ weeks. Among those who had resumed postpartum sexual intercourse, more than half had done so at 6 weeks or earlier. Many Iban mothers had resumed sexual intercourse with no contraceptive cover. The determinants of early sexual intercourse are mothers' and husbands' income, contraceptive use and mothers who believed their husbands practiced sexual abstinence while they were in confinement. Counselling on postpartum resumption of sexual intercourse should consider these determinants to ensure a more effective outcome among Iban mothers.

\section{ACKNOWLEDGEMENTS}

This study was funded by Universiti Kebangsaan Malaysia Research Fund, Project No. FF-163-2006. We would like to thank the Director-General of Health Malaysia, Deputy Director-General of Health Malaysia (Research and Technical Support), and the Director of the Institute for Medical Research (IMR) for permission to publish this paper.

\section{Funding: UKMMC Fundamental Grant \\ Competing interests: None declared \\ Ethical approval: Approved by Research and Ethics Committee Medical Faculty Universiti Kebangsaan Malaysia and Medical and Research Ethics Committee}




\section{REFERENCES}

1. WHO. Postpartum Care of the Mother And Newborn: A Practical Guide. Geneva: World Health Organization. 1998. Available at http://www.who.int/maternal_child_adolescent/docu ments/who_rht_msm_983/en/index.html.

2. ARROW. Beijing Monitoring Report. Women's Health Needs and Rights in Southern Asia. Kuala Lumpur: Asian Pacific Resource and Research Centre for Women. 2001.

3. Demyttenaere K, Gheldof K, Van Assche, FA. Sexuality in the postpartum period: a review. Curr Obstet and Gynaecol 1995;5:81-4.

4. Von Sydow K. Sexuality during pregnancy and after childbirth: a metacontent analysis of 59 studies. J Psychosom Res 1999;47:27-49.

5. Thi LM, Pasandarnton W, Rauyajin O. Traditional postpartum practices among Vietnamese mother in Anthi District, Hung Yen Province. 2004 Available at http://www.sh.mahidol.ac.th/hssip/theses/3.pdf.

6. Degrees-du-Lou, Brou H. Resumption of sexual relations following childbirth: norms, practices and reproductive health issues in Abidjan, Cote d'Ivoire. Reprod Health Matters 2005;13:155-63.

7. Kelly LS, Sheedar J, Steven-Simons C. Why lightning strikes twice: postpartum resumption of sexual activity during adolescent. J Pediatr Adolesc Gynecol 2005;18:327-35.

8. Zhu BP, Rolfs RT, Nangle BE. Effect of the interval between pregnancies on perinatal outcomes. N Engl J Med 1999;340:589-94.

9. Gurel SA, Gurel H. The evaluation of the determinants of early postpartum low mood: the importance of parity and inter-pregnancy interval. Eur J Obstet Gynecol Reprod Biol 2000;91:21-4.
10. Rosen K, Brown C, Heiman J, Leiblum S, Meston C, Shabsigh C, Ferguson D, D'Agostino R. The Female Sexual Function Index (FSFI): A multidimensional self-report instrument for the assessment of female sexual function. J Sex Marital Therapy 2000;26:191-208.

11. Woranitat W, Taneepanichskul S. Sexual function during the postpartum period. J Med Assoc Thai 2007;90:1744-8.

12. Egbuonu I, Ezechukwu CC, Chukwuka JO, Ikechebelu JI. Breastfeeding, return of menses, sexual activity and contraceptive practices among mothers in the first six months of lactation in Onitsha, South Eastern Nigeria. J Obstet Gynaecol 2005;25:500-3.

13. Rowland M, Foxcroft L, Hopman WM, Patel R. Breastfeeding and sexuality immediately postpartum. Can Fam Physician 2005;51:1366-7.

14. Kaewsarn P, Moyle W, Creedy D. Traditional postpartum practices among Thai women. J Adv Nurs 2003;41:358-66.

15. Upadhyay UD, Hindin MJ. Do higher status and more autonomous women have longer birth intervals. Soc Sci Med 2005;60:2641-55.

16. Cleland JG, Ali MM, Capo-Chichi. Postpartum sexual abstinence in West Africa: implications of AIDS control and family planning programmes. AIDS 1999;13:125-31.

17. Lawoyin TO, Osinowo H, Walker M. Sexual networking among married men with wives of childbearing age in Ibadan City, Nigeria: report of a pilot study. Afr J Med Med Sci 2004;33:207-12.

18. Awusabo-Asare K, Anarfi JK. Postpartum sexual abstinence in the era of AIDS in Ghana: prospects for change. Health Transit Rev 1997;7:257-70.

DOI: $10.5455 / 2320-1770 . i j r \operatorname{cog} 20130603$

Cite this article as: Radziah M, Shamsuddin K, Jamsiah M, Normi M, Zahari THM, Syimah ATN, Asiah MN. Early resumption of sexual intercourse and its determinants among postpartum Iban mothers. Int J Reprod Contracept Obstet Gynecol $2013 ; 2: 124-9$. 